\title{
Targeting the Hedgehog pathway in combination with X-ray or carbon ion radiation decreases migration of MCF-7 breast cancer cells
}

\author{
KATRIEN KONINGS ${ }^{1,2}$, NIELS BELMANS ${ }^{1,3}$, RANDY VERMEESEN ${ }^{1}$, BJORN BASELET $^{1}$, GRETA LAMERS $^{1}$, \\ ANN JANSSEN $^{1}$, SOFIE ISEBAERT ${ }^{2,4}$, SARAH BAATOUT ${ }^{1}$, KARIN HAUSTERMANS ${ }^{2,4}$ and MARJAN MOREELS ${ }^{1}$ \\ ${ }^{1}$ Radiobiology Unit, Institute for Environment, Health and Safety, Belgian Nuclear Research Centre $(\mathrm{SCK} \cdot \mathrm{CEN}), \mathrm{Antwerp}$, \\ $2400 \mathrm{Mol} ;{ }^{2}$ Laboratory of Experimental Radiotherapy, Department of Oncology, KU Leuven, Flemish-Brabant, 3000 Leuven; \\ ${ }^{3}$ Laboratory of Morphology, Biomedical Research Institute (BIOMED), Hasselt University, Limburg, 3590 Diepenbeek; \\ ${ }^{4}$ Department of Radiation Oncology, University Hospitals Leuven, Flemish-Brabant, 3000 Leuven, Belgium
}

Received January 11, 2019; Accepted August 28, 2019

DOI: 10.3892/ijo.2019.4901

\begin{abstract}
The use of carbon ion therapy for cancer treatment is becoming more widespread due to the advantages of carbon ions compared with X-rays. Breast cancer patients may benefit from these advantages, as the surrounding healthy tissues receive a lower dose, and the increased biological effectiveness of carbon ions can better control radioresistant cancer cells. Accumulating evidence indicates that the Hedgehog ( $\mathrm{Hh})$ pathway is linked to the development and progression of breast cancer, as well as to resistance to X-irradiation and the migratory capacity of cancer cells. Hence, there is an increasing interest in targeting the $\mathrm{Hh}$ pathway in combination with radiotherapy. Several studies have already investigated this treatment strategy with conventional radiotherapy. However, to the best of our knowledge, the combination of Hh inhibitors with particle therapy has not yet been explored. The aim of the present study was to investigate the potential of the $\mathrm{Hh}$ inhibitor GANT61 as an effective modulator of radiosensitivity and migration potential in MCF-7 breast cancer cells, and compare potential differences between carbon ion irradiation and X-ray exposure. Although Hh targeting was not able to radiosensitise cells to any radiation type used, the combination of GANT61 with X-rays or carbon ions (energy: $95 \mathrm{MeV} / \mathrm{n}$; linear energy transfer: $73 \mathrm{keV} / \mu \mathrm{m}$ ) was more effective in decreasing MCF-7 cell migration compared with either radiation type alone. Gene expression of the Hh pathway was affected to different degrees in response to X-ray and carbon ion irradiation, as well as in response to the combination of GANT61 with irradiation. In
\end{abstract}

Correspondence to: Dr Marjan Moreels, Radiobiology Unit, Institute for Environment, Health and Safety, Belgian Nuclear Research Centre, Boeretang 200, Antwerp, 2400 Mol, Belgium E-mail: marjan.moreels@sckcen.be

Key words: carbon ion irradiation, radiosensitisation, Hedgehog pathway, cell migration, gene expression, GANT61 conclusion, combining $\mathrm{Hh}$ inhibition with radiation (X-rays or carbon ions) more effectively decreased breast cancer cell migration compared with radiation treatment alone.

\section{Introduction}

The use of charged particles, such as protons or carbon ions, in radiotherapy offers several advantages compared with conventional radiotherapy with X-rays. One of these advantages is the superior dose deposition due to the physical properties of the particles $(1,2)$. Therefore, the healthy tissue surrounding the tumour receive a lower radiation dose and, consequently, fewer side effects are expected. In addition, carbon ions have increased relative biological effectiveness (RBE), which indicates that these particles are more effective in inducing DNA damage, cell cycle arrest and cell death compared with X-rays $(1,3,4)$. Due to these advantages, the number of cancer patients receiving carbon ion therapy, particularly for radioresistant tumours, is increasing (5).

Breast cancer is the most common cancer in women worldwide, and the majority of these patients are treated with surgery and/or radiotherapy (6). Radiotherapy-related long-term effects include cardiopulmonary toxicity and secondary malignancies (7). Particle therapy may benefit breast cancer patients by decreasing the exposure of the heart and lungs, thereby decreasing cardiotoxicity (8). In Japan, carbon ion therapy has already been used to treat stage I breast cancer (9). The rationale for using carbon ions in early-stage breast cancer is the fact that radical conventional radiotherapy is associated with an inferior cosmetic outcome, unsatisfactory results and technical difficulties, which are not observed with carbon ions (9). In Europe, however, breast cancer has only been treated with proton therapy and in only few particle therapy centres (10).

Despite the fact that primary breast cancer is associated with a good local control rate, 25-50\% of breast cancer patients will ultimately develop metastases (11), which is considered to be an incurable disease state (12). The migration and invasion of cancer cells is a complicated process that involves the interplay of different molecular pathways, including the 
Hedgehog (Hh) signalling pathway. This is an important developmental pathway that has also been implicated in the growth and progression of different tumour types, including breast cancer (13-15). Several studies have observed overexpression of the Hh pathway genes sonic Hedgehog (SHH), glioma-associated oncogene (GLI)1 and patched 1 (PTCH1) in breast cancer cells $(15,16)$. Moreover, in a study by Cui $\mathrm{et} \mathrm{al}$, upregulation of SHH was observed in early-stage breast cancer, which may be an indication that Hh pathway activation is an early event in breast cancer development (17). Several in vitro and in vivo studies have also reported that active $\mathrm{Hh}$ signalling is associated with increased migration and invasion of different types of cancer cells (18-23), while inhibition of GLI1/2 has been found to decrease the migration of ovarian cancer and medulloblastoma cells $(24,25)$. In addition, the Hh pathway has also been implicated in resistance to photon radiation $(18,26,27)$.

Hence, there is an increasing interest in targeting the $\mathrm{Hh}$ pathway for different tumour types. Furthermore, combining Hh inhibitors with radiation therapy may sensitise cancer cells to radiation. Several studies have already investigated this treatment strategy with conventional radiotherapy, mostly using inhibitors that target the Hh pathway further upstream, such as smoothened (SMO) inhibitors (28-35). However, resistance to SMO inhibitors has already been observed (36-38). Therefore, targeting the Hh pathway further downstream, at the level of the GLI1/2 transcription factors, appears to be a more promising approach $(29,39,40)$.

Thus far, the combination of targeted drugs with particle therapy has not been explored to the same extent as with $\mathrm{X}$-rays. One example is the combination of poly(ADP-ribose) polymerase inhibitors with carbon ion radiation, which has demonstrated an increased sensitivity of cancer cells to particle radiation (41). However, to the best of our knowledge, the combination of particle therapy with Hh inhibitors has not been previously investigated.

The aim of the present study was to compare the effect of X-rays and carbon ions on cell survival, migration and $\mathrm{Hh}$ pathway gene expression in breast cancer cells, and determine how this gene expression may be associated with cellular behaviour, such as migration. In addition, the potential of the Hh inhibitor GANT61 as an effective modulator of cancer cell radiosensitivity and migration potential was explored.

\section{Materials and methods}

Cell line and drug preparation. Human breast cancer cells (MCF-7) were obtained from the American Type Culture Collection (ATCC). The MCF-7 cells are breast cancer cells derived from a pleural effusion (metastatic site) (42). The MCF-7 cell line was selected because different components of the Hh signalling pathway are expressed in these cells (data not shown). The cells were cultured in Eagle's minimal essential medium (ATCC) supplemented with $10 \%$ foetal bovine serum (FBS), and maintained in a humidified incubator $\left(37^{\circ} \mathrm{C}\right.$ and $5 \% \mathrm{CO}_{2}$ ). Mycoplasma testing was performed periodically.

The GLI1/2 inhibitor GANT61 (Selleck Chemicals) was selected to inhibit the Hh pathway. Two concentrations of GANT61 (1 and $10 \mu \mathrm{mol} / \mathrm{l})$ were dissolved in dimethyl sulphoxide (DMSO), aliquoted and stored at $-20^{\circ} \mathrm{C}$. Only data relating to $10 \mu \mathrm{mol} / 1$ GANT61 will be discussed, since this was the only concentration where significant changes were observed compared with the DMSO-treated control (Fig. 1). Control cells were treated with the drug solvent, with a final dilution of DMSO in the cell medium of 1:1,000. The drug was added $72 \mathrm{~h}$ prior to irradiation with either X-rays or carbon ions, based on previous studies using GANT61 $(29,39)$. The drug was present in the medium during irradiation until the cells had to be processed for the different assays. After processing of the cells for the different assays, the drug was removed.

Cytotoxicity screening. The effect of the Hh inhibitor GANT61 on MCF-7 cell cytotoxicity was assessed by means of a sulphorhodamine B (SRB) assay. MCF-7 cells were seeded in 96-well plates $(2,500$ cells/well). After $72 \mathrm{~h}$ of treatment with DMSO (1:1,000), $1 \mu \mathrm{mol} / 1$ GANT61 or $10 \mu \mathrm{mol} / 1$ GANT61 cells were fixed with trichloric acid and stained with $0.4 \%$ SRB (Sigma Aldrich; Merck KGaA) in $1 \%$ acetic acid. The cells were washed five times with $1 \%$ acetic acid, after which time $10 \mu \mathrm{mol} / 1$ Tris-Base was added. The absorbance was measured at $570 \mathrm{~nm}$ with a CLARIOstar microplate reader (BMG Labtech).

$X$-irradiation. To irradiate MCF-7 cells with X-rays, the Xstrahl $320 \mathrm{kV}$ generator $(250 \mathrm{kV}, 12 \mathrm{~mA}, 3.8 \mathrm{~mm} \mathrm{Al}$ and $1.4 \mathrm{~mm} \mathrm{Cu}$ ) was used at the $\mathrm{SCK} \cdot \mathrm{CEN}$ facility (Mol, Belgium). Cells were irradiated at room temperature with different X-ray doses $(0,0.25,0.5,2,4$ and $6 \mathrm{~Gy})$ at a calculated dose rate of $0.5 \mathrm{~Gy} / \mathrm{min}$. The culture medium was replaced prior to irradiation in a horizontal position (perpendicular to the vertical X-ray beam). The irradiation of biological samples was performed with the Xstrahl $320 \mathrm{kV}$ tube, using the ISO $4037 \mathrm{H}-250$ beam quality in the following configuration: Inherent filtration: $0.21 \mathrm{~mm} \mathrm{Al}$; additional filtration: $3.8 \mathrm{~mm} \mathrm{Al}+1.4 \mathrm{~mm} \mathrm{Cu}+$ dose-area product meter; tube voltage: $250 \mathrm{kV}$; tube current: $12 \mathrm{~mA}$; distance: $50 \mathrm{~cm}$. A Farmer NE2571 chamber was used for dosimetry measurements. The calibration in terms of $\mathrm{K}_{\text {air }}$ of this chamber was based on the primary standards of the Physikalisch Technische Bundesanstalt, Germany.

Carbon ion irradiation. Carbon ion beam time was granted by the iPAC committee of the Grand Accélérateur National d'Ions Lourds (GANIL). The cells were transported from Belgium to France by car, inside a transportable incubator, in completely filled flasks. Upon arrival, fresh culture medium was added, and the cells were placed in a humidified incubator overnight. Four days prior to irradiation, the cells were seeded in $12.5-\mathrm{cm}^{2}$ flasks (Falcon, VWR). Immediately prior to irradiation, the cell culture flasks were completely filled with medium due to the vertical position (perpendicular to the horizontal carbon ion beam) during irradiation. Irradiation of the cells was performed at room temperature, with an initial carbon ion beam energy of 95 and $26-27 \mathrm{MeV} / \mathrm{u}$ on target. A polymethylmethacrylate degrader of $16.9 \mathrm{~mm}$ was used to obtain a linear energy transfer (LET) of $73 \mathrm{keV} / \mu \mathrm{m}$. The carbon ion beam had a range in water of $2.5-2.4 \mathrm{~mm}$. The doses applied were $0,0.25,0.5,1,2,3$ and $4 \mathrm{~Gy}$, with a calculated dose rate of $\sim 2 \mathrm{~Gy} / \mathrm{min}$. Carbon ion dosimetry was performed as previously described (43). 


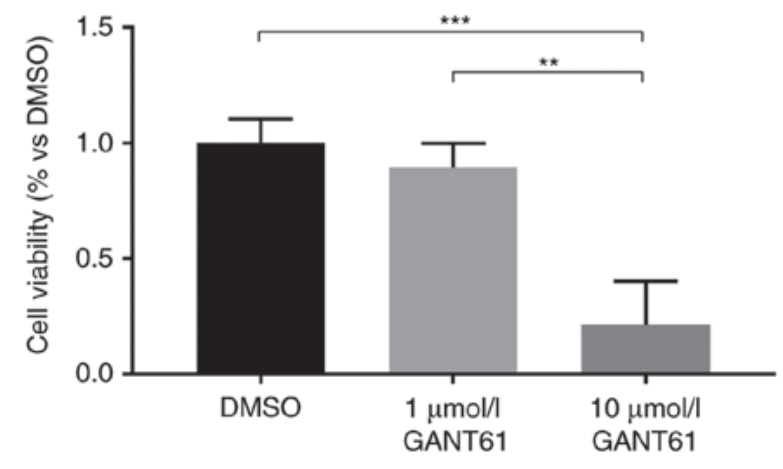

Figure 1. Effect of Hedgehog pathway inhibition by different concentrations of GANT61 on MCF-7 cell survival. The viability of MCF-7 cells was measured after $72 \mathrm{~h}$ of incubation with DMSO $(1: 1,000), 1$ or $10 \mu$ M GANT61. The results are presented as means \pm standard error of the mean of three independent experiments performed in quadruplicate. ${ }^{* *} \mathrm{P} \leq 0.01 ;{ }^{* * *} \mathrm{P} \leq 0.001$.

Colony survival assay. Immediately after irradiation of the cells in the culture flasks, the cells were trypsinized and seeded in triplicate in 6-well plates at low densities (ranging from 800 cells/well when exposed to the lowest dose to 24.000 cells/well when exposed to the highest dose). At 14 days after seeding, the cells were fixed with $6 \%$ glutaraldehyde and $0.5 \%$ crystal violet solution (Sigma-Aldrich; Merck KGaA). Colonies of $>50$ cells were counted with a ColCount colony counter (Oxford Optronix) and used to calculate the surviving fraction (SF) with the linear quadratic model, as previously described (44). The RBE was calculated at $10 \%$ survival by dividing the dose of $\mathrm{X}$-rays at $\mathrm{SF}_{10}$ by the dose of carbon ions at $\mathrm{SF}_{10}$. Plating efficiency between the DMSO-treated cells and the GANT61-treated cells differed only slightly (max. 10\% difference).

Gene expression analysis. RNA was isolated at 8 and $24 \mathrm{~h}$ after irradiation using the Allprep DNA/RNA kit (Qiagen) in accordance with the manufacturer's protocol. The RNA concentration was measured using DropSense 16 (Trinean), and RNA quality was controlled using the Agilent 2100 Bioanalyzer (Agilent Technologies, Inc.). Subsequently, RNA was reverse-transcribed to cDNA using the GoScript ${ }^{\mathrm{TM}}$ Reverse Transcription System (Promega Corporation). Finally, qPCR reactions were performed by the 7500 Fast Real Time PCR System (Applied Biosystems; Thermo Fisher Scientific, Inc.) using MESAGreen qPCR Master Mix Plus for SYBR ${ }^{\circledR}$ Assay Low ROX (Eurogentec). The following thermocycling conditions were used: $5 \mathrm{~min}$ at $95^{\circ} \mathrm{C}$ followed by 40 cycles of $3 \mathrm{sec}$ at $95^{\circ} \mathrm{C}$ and $45 \mathrm{sec}$ at $60^{\circ} \mathrm{C}$. The primers for the $\mathrm{Hh}$ pathway genes [SHH, PTCH1, SMO, GLI1, GLI2, GLI3 and suppressor of fused homolog (SUFU)] and target genes of the Hh pathway [cyclin D1 (CCND1), vascular endothelial growth factor (VEGF)A, B-cell lymphoma (BCL)-2, SNAIL1 and matrix metallopeptidase (MMP)9] are listed in Table I. Specific target genes of the Hh pathway were selected based on their involvement in cell cycle regulation (CCND1), apoptosis (BCL-2), epithelial-to-mesenchymal transition (EMT; VEGFA and MMP-9) or migration (SNAIL). The gene expression was normalized to two housekeeping genes (GAPDH and HPRT1) and calculated using the Pfaffl method (45). The Pfaffl method was selected, as it takes into account the individual

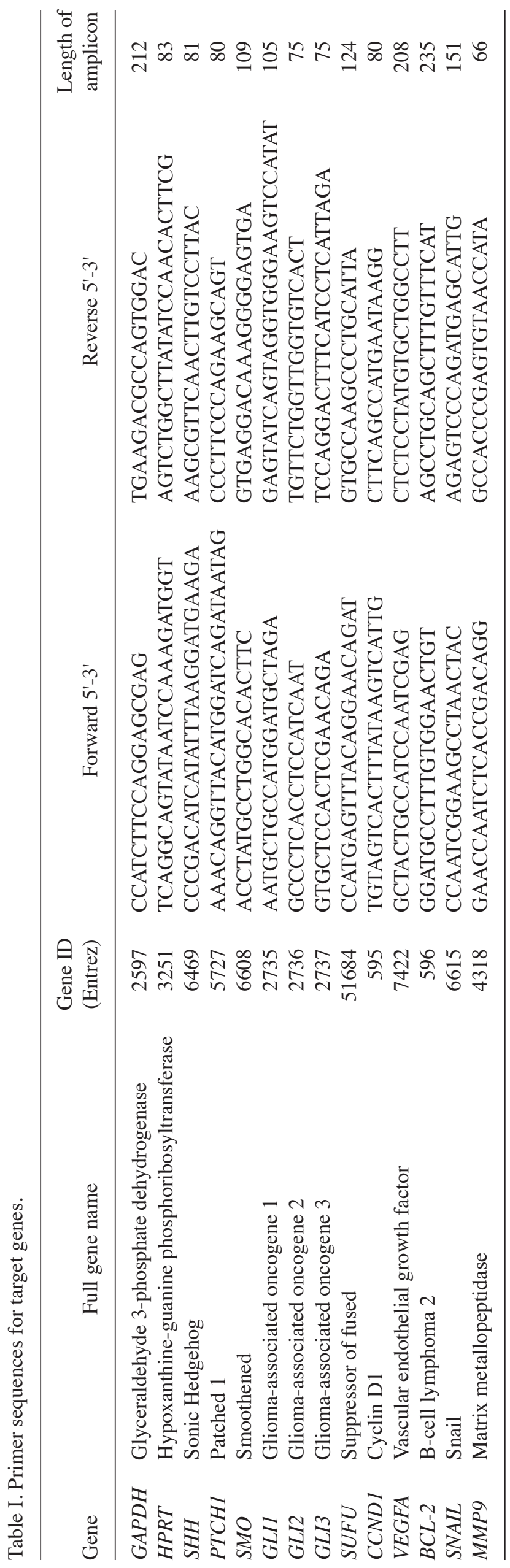


reaction efficiencies of the housekeeping genes and the target genes (45).

Boyden chamber assay. The Boyden chamber assay (Neuroprobe) was used to investigate the migratory potential of cancer cells after irradiation. Briefly, cells were seeded in serum-free medium in the upper wells of the Boyden chamber $24 \mathrm{~h}$ after irradiation. The lower wells were filled with medium containing $0.1 \%$ FBS. The upper wells were separated from the lower wells by a polycarbonate membrane with $8-\mu \mathrm{m}$ pores (Neuroprobe). The membrane was precoated with collagen I (Gibco; Thermo Fisher Scientific, Inc.). After the cells had been allowed to migrate for $16 \mathrm{~h}$, they were fixed with methanol and stained with $0.5 \%$ crystal violet solution. Images were captured with a Leica MZ12 microscope (Leica Microsystems, Ltd.), and the migrated cells were counted in five separate fields using Image $\mathbf{J}$ software (National Institutes of Health).

Statistical analysis. The experiments were repeated at least three times for X-ray experiments and at least twice for carbon ion experiments. More specifically, for carbon ion irradiation, the colony survival assay was performed in three different experiments with two technical repeats per dose. The Boyden chamber assay was performed twice with three technical repeats per dose. The gene expression experiments were performed in two independent beam times with four technical repeats per dose. The results are expressed as means \pm standard error of the mean. Statistical analysis was performed using GraphPad Prism 7 (GraphPad Software, Inc.). For all experiments, one-way ANOVA with Tukey's multiple comparison test or a two-tailed Student's t-test was performed. P-values $\leq 0.05$ were considered to indicate statistically significant differences.

\section{Results}

$X$-ray and carbon ion radiation decrease the migration of MCF-7 cells. Both X-rays and carbon ions were able to induce a dose-dependent decrease in the migration of MCF-7 cells (Fig. 2). No significant differences were observed between the two radiation types, except at $0.25 \mathrm{~Gy}$, where X-rays decreased cell migration significantly more notably compared with carbon ions.

Each radiation type induces a specific gene expression profile of the Hh pathway and its target genes. Altered expression of the investigated Hh pathway genes and certain selected target genes was observed after irradiation with either X-rays or carbon ions when compared with non-irradiated controls (Fig. 3). In addition, both irradiation types induced their own specific expression profile of the Hh pathway and its target genes. Significant downregulation of GLI1 was observed at $8 \mathrm{~h}$ after $\mathrm{X}$-ray radiation $(\mathrm{P}<0.0001)$. In addition, GLI3 also exhibited a persistent downregulation (until $24 \mathrm{~h}$ after a 4-Gy dose of X-rays). Carbon ions significantly decreased PTCH1 expression at $8 \mathrm{~h}$ after exposure $(0.5 \mathrm{~Gy}: \mathrm{P}=0.0005$; 2 Gy: $\mathrm{P}=0.0024$; and 4 Gy: $\mathrm{P}=0.002)$. GLI3 and SUFU, both of which are Hh pathway inhibitors, exhibited a significant upregulation at $24 \mathrm{~h}$ after a 2- and 4-Gy dose of carbon ions (GLI3: $\mathrm{P}<0.0001$; SUFU 2 Gy: $\mathrm{P}=0.0003$ and 4 Gy: $\mathrm{P}=0.01$ ).

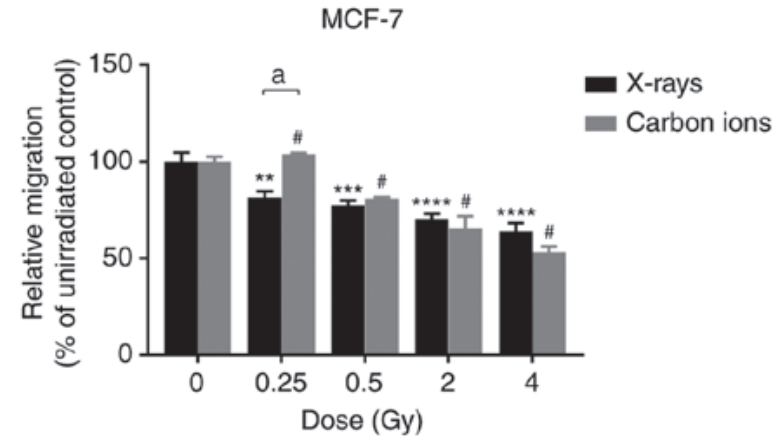

Figure 2. Migration of MCF-7 cells after irradiation. The migratory potential of MCF-7 cells was assessed after irradiation with X-rays (black) or carbon ions (grey) by means of a Boyden chamber. The number of migrated cells after treatment was counted and compared to the number of cells migrated after control treatment (relative migration). The results are presented as means \pm standard error of the mean of three independent experiments performed in triplicate. ${ }^{\text {a }} \mathrm{P} \leq 0.0001$ compared with $0.25 \mathrm{~Gy}$ of $\mathrm{X}$-rays. ${ }^{\#} \mathrm{P} \leq 0.0001$ compared with $0 \mathrm{~Gy}$ of carbon ions. ${ }^{* *} \mathrm{P} \leq 0.01$ compared with $0 \mathrm{~Gy}$ of X-rays. ${ }^{* * *} \mathrm{P} \leq 0.001$ and ${ }^{* * * *} \mathrm{P} \leq 0.0001$.

For the Hh pathway target genes BCL-2 (2 and 4 Gy) and VEGFA (all doses), X-rays significantly downregulated their expression at $8 \mathrm{~h}$ after irradiation (BCL-2 2 Gy: $\mathrm{P}=0.0019$ and $4 \mathrm{~Gy}: \mathrm{P}<0.0001$; VEGFA $0.5 \mathrm{~Gy}: \mathrm{P}=0.03$, 2 Gy: $\mathrm{P}=0.0026$ and $4 \mathrm{~Gy}: \mathrm{P}=0.0028$ ). Carbon ions ( 2 and 4 Gy) also significantly downregulated BCL-2 and VEGFA expression at $8 \mathrm{~h}$ after exposure (BCL-2 $2 \mathrm{~Gy}: \mathrm{P}=0.001$ and 4 Gy: $\mathrm{P}=0.0007$; VEGFA 2 Gy: $\mathrm{P}=0.02$ and $4 \mathrm{~Gy}: \mathrm{P}=0.001$ ). At $24 \mathrm{~h}$ after carbon ion irradiation, an upregulation in the target genes was observed, particularly CCND1, VEGFA and MMP9, while both up- and downregulation were observed after X-ray irradiation.

GANT61 does not affect the sensitivity of MCF-7 cells to $X$-ray or carbon ion radiation. A dose-dependent decrease in MCF-7 cell survival was observed after irradiation with either $\mathrm{X}$-rays or carbon ions (Fig. 4A). Carbon ions, however, were more effective than X-rays in terms of lowering the surviving fraction, with a calculated RBE of 2.12 for carbon ions at $10 \%$ survival $\left(\mathrm{RBE}_{10}\right)$.

The combination of the Hh pathway inhibitor GANT61 with different doses of $\mathrm{X}$-rays or carbon ions was not able to exert a radiosensitising effect on MCF-7 cells (Fig. 4B and C). No significant differences in the dose enhancement factor at $10 \%$ survival (DEF 0.1) were observed, based on a DEF 0.1 of 0.97 and 1.02 for X-rays and carbon ions, respectively. The plating efficiencies were calculated and were found to be 0.71 for the combination of X-rays with $10 \mu \mathrm{mol} / 1$ GANT61 and 0.64 for the combination of carbon ions with $10 \mu \mathrm{mol} / 1$ GANT61.

Combining radiation with GANT61 affects migration differently compared with either radiation type alone. The combination of GANT61 with X-rays was able to significantly suppress the migration of MCF-7 cells compared with X-rays alone, at a dose of $0.5(\mathrm{P}=0.049)$ and $4 \mathrm{~Gy}(\mathrm{P}=0.0087)$ (Fig. 5). However, GANT61 in combination with carbon ions was only able to significantly decrease the migration of $\mathrm{MCF}-7$ cells at a dose of $0.5(\mathrm{P}<0.0001)$ and $4 \mathrm{~Gy}(\mathrm{P}=0.0007)$ (Fig. 5). 


\begin{tabular}{|c|c|c|c|c|c|c|c|c|c|c|c|c|}
\hline \multirow{3}{*}{ MCF-7 } & \multicolumn{6}{|c|}{ X-rays } & \multicolumn{6}{|c|}{ Carbon ions } \\
\hline & \multicolumn{3}{|c|}{$8 \mathrm{~h}$} & \multicolumn{3}{|c|}{$24 \mathrm{~h}$} & \multicolumn{3}{|c|}{$8 \mathrm{~h}$} & \multicolumn{3}{|c|}{$24 \mathrm{~h}$} \\
\hline & $0.5 \mathrm{~Gy}$ & 2 Gy & 4 Gy & $0.5 \mathrm{~Gy}$ & 2 Gy & 4 Gy & 0.5 Gy & 2 Gy & 4 Gy & $0.5 \mathrm{~Gy}$ & 2 Gy & 4 Gy \\
\hline
\end{tabular}

Hh pathway genes

\begin{tabular}{|l|l|l|l|l|l|l|l|l|l|l|l|}
\hline SHH & & & & & & & & & & & \\
\hline PTCH1 & & & & & & & & & & & \\
\hline SMO & & & & & & & & & & & \\
\hline GLI1 & & & & & & & & & & & \\
\hline GLI2 & & & & & & & & & & & \\
\hline GLI3 & & & & & & & & & & & \\
\hline SUFU & & & & & & & & & & & \\
\hline
\end{tabular}

Target genes of the Hh pathway

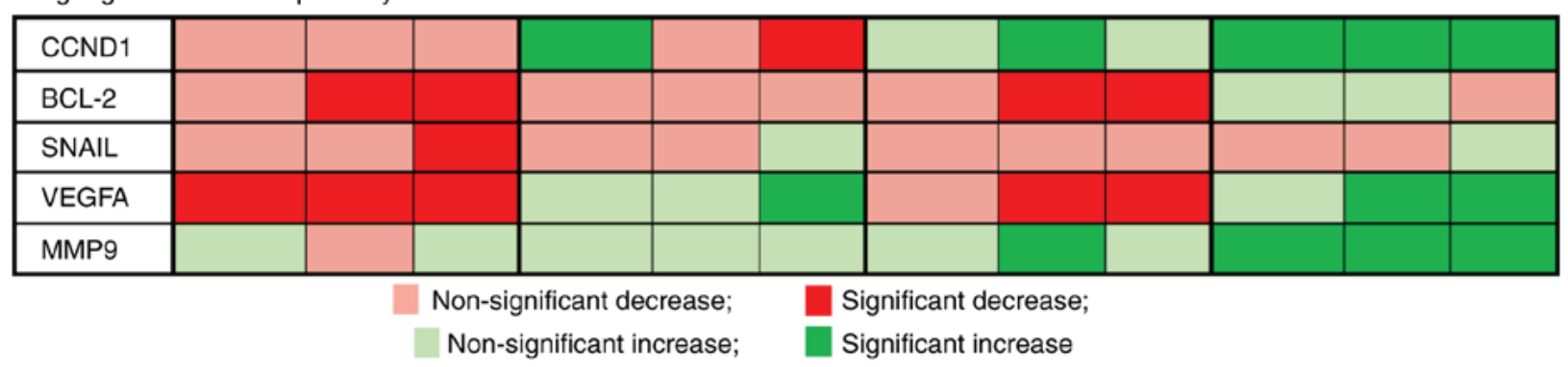

Figure 3. Hedgehog $(\mathrm{Hh})$ pathway gene expression in MCF-7 cells after irradiation. MCF-7 cells were irradiated with different doses of X-rays or carbon ions. The expression of the Hh pathway genes and target genes was investigated at 8 and $24 \mathrm{~h}$ after irradiation. Different colours represent statistical significance (compared with control, 0 Gy): Light red, non-significant decrease; bright red, significant decrease; light green, non-significant increase; and bright green, significant increase.
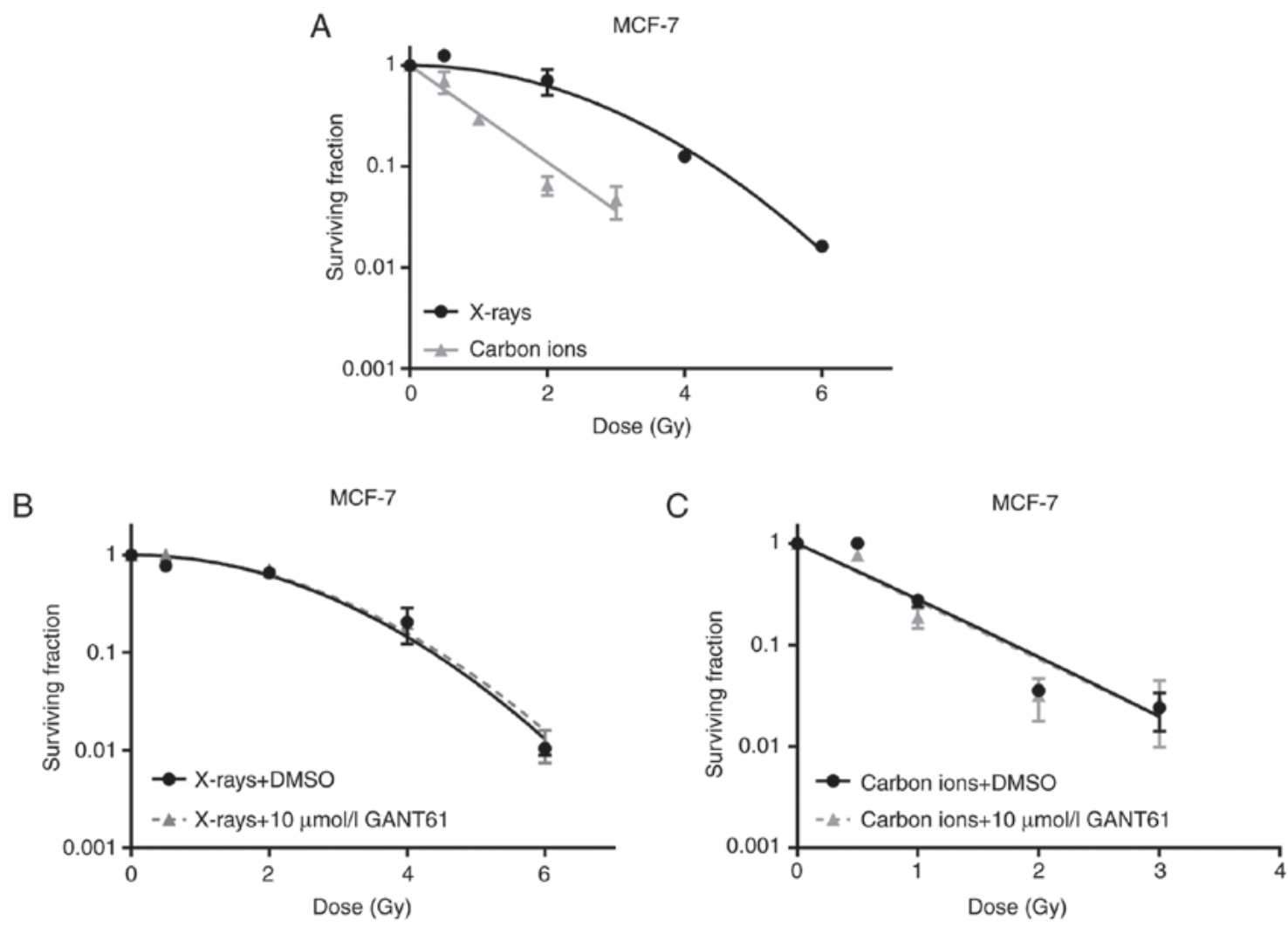

Figure 4. Effect of different radiation types with or without GANT61 on the survival of MCF-7 cells. (A) MCF-7 cells were irradiated with different doses of X-rays or carbon ions and colony formation was assessed 14 days after exposure, as stated in Materials and methods. Colony survival curves of GANT61-pretreated MCF-7 cells irradiated with (B) X-rays or (C) carbon ions were drawn. DMSO-treated cell cultures were used as control. The results are presented as means \pm standard error of the mean of three independent experiments performed in triplicate. 


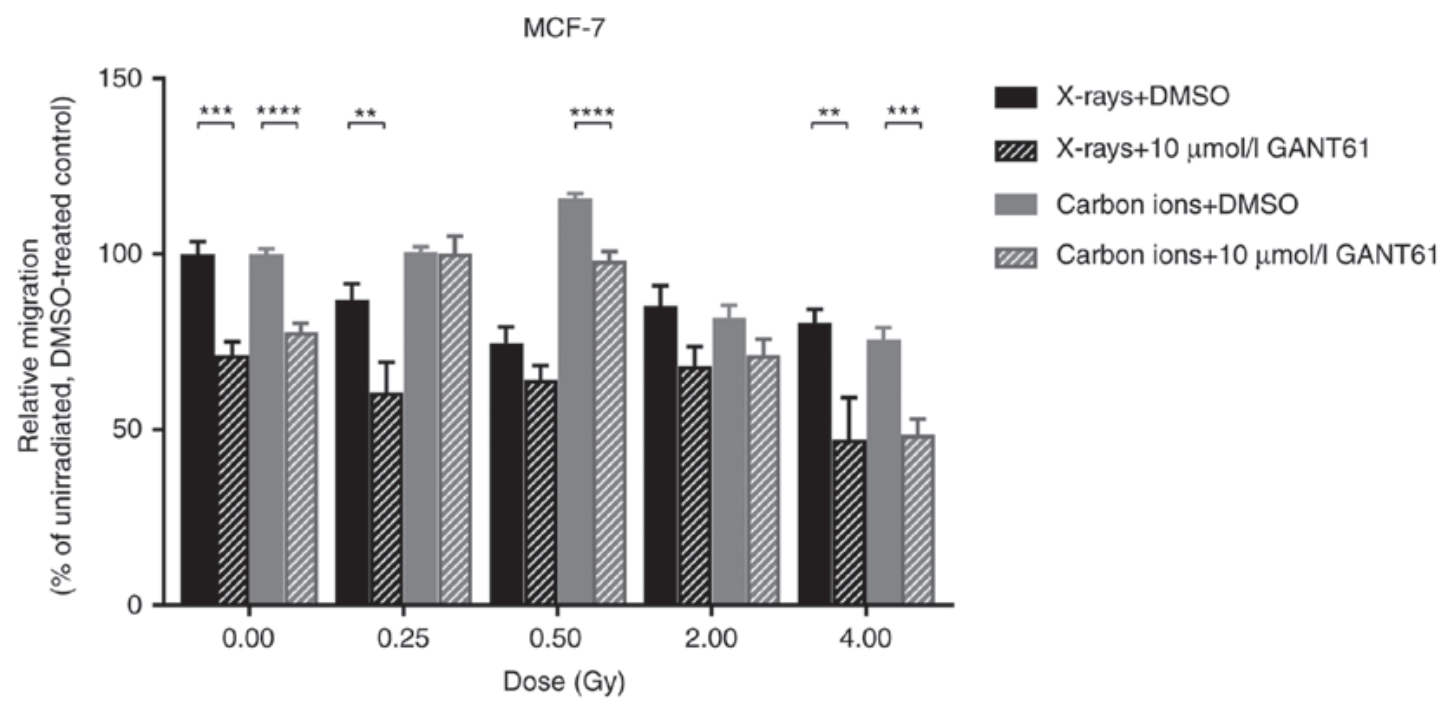

Figure 5. Migration of MCF-7 cells following combination of GANT61 with irradiation. The migratory potential of MCF-7 cells was assessed by Boyden chamber after X-rays and DMSO (black), X-rays and GANT61 (black shaded), carbon ions and DMSO (grey) and carbon ions and GANT61 (grey shaded). The number of migrated cells after treatment was counted and compared to the number of cells migrated after control treatment (relative migration). The results are presented as means \pm standard error of the mean of two to three independent experiments performed in triplicate. ${ }^{*} \mathrm{P} \leq 0.05$ vs. control cells; ${ }^{* *} \mathrm{P} \leq 0.01$; ${ }^{* * * *} \mathrm{P} \leq 0.001 ;{ }^{* * * * *} \mathrm{P} \leq 0.0001$.

GANT61 induces a differential expression in Hh pathway and Hh target genes in combination with X-rays or carbon ions. The combination of GANT61 with X-rays was able to induce more significant changes in the expression of the Hh target genes compared with the combination of GANT61 with carbon ions (Fig. 6; control: DMSO-treated cells). The majority of the Hh pathway genes exhibited a significant $(\mathrm{SHH}$ : $\mathrm{P}=0.04$, PTCH1: $\mathrm{P}=0.01$, GLI2: $\mathrm{P} \leq 0.0001$ and GLI3 $\mathrm{P}=0.0005$ ) downregulation $8 \mathrm{~h}$ after $4 \mathrm{~Gy}$ of X-rays and GANT61, apart from SMO, which exhibited a significant upregulation $(\mathrm{P}=0.002)$. At $24 \mathrm{~h}$ after the combination of X-rays and GANT61, a significant downregulation was observed only for SMO, whereas the remaining genes were upregulated. Carbon ions were able to significantly downregulate $\mathrm{SHH}$ at $8 \mathrm{~h}$ post-irradiation (2 Gy: $\mathrm{P}<0.0001)$, PTCH1 (0.5 Gy: $\mathrm{P}<0.0001$ and $2 \mathrm{~Gy}: \mathrm{P}=0.0002)$ and SMO (0.5 Gy: $\mathrm{P}=0.03,2$ Gy: $\mathrm{P}=0.0002$ and $4 \mathrm{~Gy}: \mathrm{P}<0.0001)$, whereas upregulation of these genes was observed at $24 \mathrm{~h}$ after exposure.

One of the target genes of the Hh pathway, CCND1, exhibited a significant downregulation, which persisted for up to $24 \mathrm{~h}$ after exposure to X-rays and GANT61 (at 8 h $0.5 \mathrm{~Gy}$ : $\mathrm{P}=0.02$, 2 Gy: $\mathrm{P}=0.01$ and $4 \mathrm{~Gy}: \mathrm{P}=0.01$; at 24 h $0.5 \mathrm{~Gy}: \mathrm{P}=0.04,2 \mathrm{~Gy}$ : $\mathrm{P}=0.0003$ and $4 \mathrm{~Gy}: \mathrm{P}=0.003)$. By contrast, VEGFA exhibited a significant upregulation at $8 \mathrm{~h}$ after X-ray and GANT61 exposure (all doses $\mathrm{P}<0.0001$ ), whereas at $24 \mathrm{~h}$ after exposure a significant downregulation (except at $2 \mathrm{~Gy}$ ) was observed (0.5 Gy: $\mathrm{P}=0.002$ and $4 \mathrm{~Gy}: \mathrm{P}=0.0007)$. The combination of carbon ions and GANT61 was able to significantly upregulate CCND1 (0.5 Gy: $\mathrm{P}=0.01,2$ Gy: $\mathrm{P}=0.04$ and $4 \mathrm{~Gy}: \mathrm{P}=0.01$ ) and BCL-2 (2 Gy: $\mathrm{P}=0.0001$ and $4 \mathrm{~Gy}: \mathrm{P}<0.0001)$ expression (except at $0.5 \mathrm{~Gy}$ ) $8 \mathrm{~h}$ after exposure, whereas a downregulation was observed at $24 \mathrm{~h}$ (except for BCL-2 at $4 \mathrm{~Gy}$ ).

\section{Discussion}

Carbon ions are superior at sparing normal tissues due to their physical characteristics, and are also known to have a higher biological effectiveness compared with X-rays (1). As such, carbon ions may be a promising treatment option for breast cancer patients. Therefore, the aim of the present study was to investigate whether carbon ions are superior to X-rays in decreasing breast cancer cell survival and migration and modulating Hh pathway gene expression. Furthermore, we aimed to investigate the potential modulatory effect of the Hh inhibitor GANT61 in combination with different radiation types for these end points.

The migration of cancer cells after radiotherapy remains a subject of debate, since contradictory results have been reported following photon irradiation: Certain studies have observed an increase in cell migration after radiation, while others have demonstrated a decrease in migration (46). For particle radiation, more specifically carbon ions, cell migration has been shown to decrease $(47,48)$. In the present study, a dose-dependent decrease in migration was observed for both X-rays and carbon ions. However, no differences were observed between carbon ions and X-rays. This is in contrast to a study published by Matsumoto et al, where a significant difference in melanoma cell migration was observed between X-ray and carbon ion irradiation (49). The lack of difference in migration after X-ray or carbon ion irradiation observed in the present study may be explained by the similar expression profile of the migration-related gene VEGFA after both $\mathrm{X}$-ray and carbon ion irradiation. In addition, the presence of a cancer stem cell (CSC) subpopulation in the MCF-7 cell line may account for the lack of difference. Moreover, it is known that CSCs are characterised by an increased resistance to radiotherapy and play an important role in treatment failure and recurrence (metastasis) (50). By contrast, a study by Zhang et al reported increased migration of MCF-7 cells after X-ray radiation (51). However, these cells were irradiated with a total dose of 20 Gy administered in daily fractions of 1 or $2 \mathrm{~Gy}$, whereas a single irradiation dose was used in the present study. Although different survival levels are observed 


\begin{tabular}{|c|c|c|c|c|c|c|c|c|c|c|c|c|}
\hline \multirow{3}{*}{ MCF-7 } & \multicolumn{6}{|c|}{ X-rays+GANT61 } & \multicolumn{6}{|c|}{ Carbon ions+GANT61 } \\
\hline & \multicolumn{3}{|c|}{$8 \mathrm{~h}$} & \multicolumn{3}{|c|}{$24 \mathrm{~h}$} & \multicolumn{3}{|c|}{$8 \mathrm{~h}$} & \multicolumn{3}{|c|}{$24 \mathrm{~h}$} \\
\hline & 0.5 Gy & 2 Gy & 4 Gy & 0.5 Gy & 2 Gy & 4 Gy & 0.5 Gy & 2 Gy & 4 Gy & $0.5 \mathrm{~Gy}$ & 2 Gy & 4 Gy \\
\hline
\end{tabular}

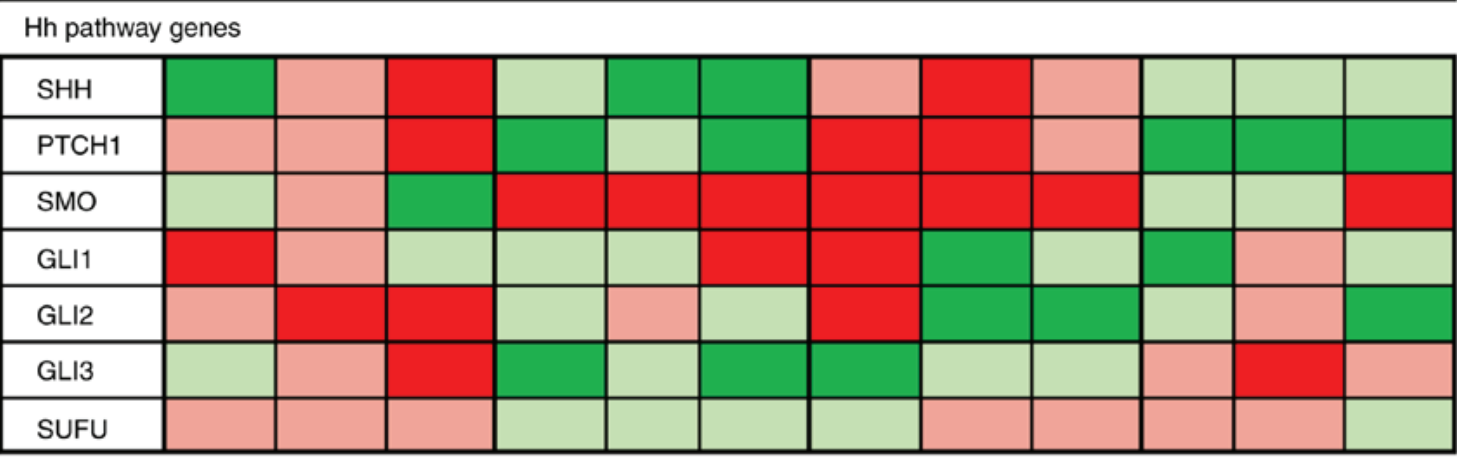

Target genes of the Hh pathway

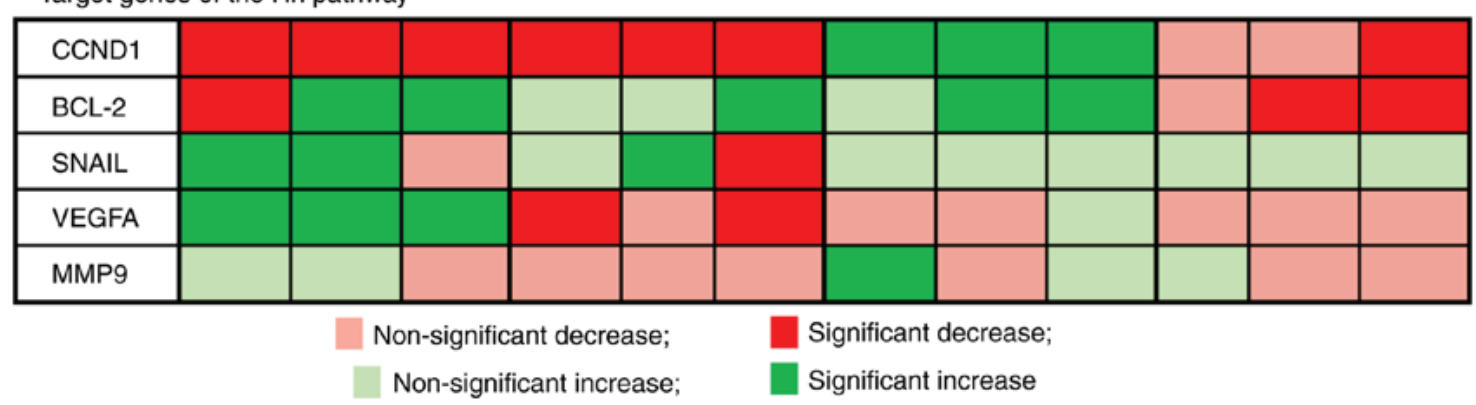

Figure 6. Hedgehog (Hh) pathway gene expression in MCF-7 cells following combination treatment with irradiation and GANT61. The expression of Hh pathway genes and target genes was assessed at 8 and $24 \mathrm{~h}$ after irradiation combined with GANT61. Different colours represent the statistical significance compared with the DMSO-treated control. Light red, non-significant decrease; bright red, significant decrease; light green, non-significant increase; and bright green, significant increase.

after X-ray and carbon ion irradiation (Fig. 4), migration is not affected in a similar manner (Fig. 2). This may be attributed to the fact that live cells were only counted prior to seeding the MCF-7 cells in the Boyden chamber. Therefore, although more cells may die after carbon ion irradiation, the difference that may exist between X-rays and carbon ions is at least partly filtered out. In addition, both assays were assessed at different time points after 14 days (colony survival assay) and $24+16 \mathrm{~h}$ (Boyden chamber assay). Considering the fact that different responses are observed after 0.5 Gy carbon ions, as shown in Fig. 2 (decreased migration) and Fig. 5 (increased migration), DMSO may exert an effect on MCF-7 cells, although we do not consider this to be significant. It has been previously reported that $0.5 \%$ DMSO may exert radioprotective effects $(52,53)$; however, at the concentration used herein $(1: 1,000)$, this would not be expected to have a major impact. In addition, both experiments [radiation alone (Fig. 2); radiation and GANT61 (Fig. 5)] were performed separately, which may account for the differences observed. For the radiation alone experiments, no DMSO was used or added to the medium, whereas for the experiments using the combination of radiation and GANT61, DMSO was added to the medium of the different conditions.

Furthermore, the present study demonstrated a time- and radiation type-dependent response in the gene expression of the $\mathrm{Hh}$ pathway and selected Hh target genes that are specifically involved in cell cycle regulation, apoptosis or cell migration. While the significantly altered genes mostly exhibited a significantly decreased expression at $8 \mathrm{~h}$ after irradiation for both radiation types, the majority of the genes exhibited a significantly increased expression at $24 \mathrm{~h}$ after irradiation with either X-rays or carbon ions. In a previous study by Fushimi et al, a significantly increased CCND1 expression at $24 \mathrm{~h}$ was observed after carbon ions (4 Gy), but not after X-rays (4 Gy), in oral squamous cell carcinoma cells (54). By contrast, a significant downregulation in CCND1 was observed after 4 Gy of X-rays (54). In addition, as the combination of X-rays and GANT61 differentially affected CCND1 expression compared with the combination of carbon ions and GANT61, it may be of interest to also investigate the effect of both treatments on the cell cycle. Overall, radiation induced a variable response in the gene expression of the $\mathrm{Hh}$ pathway genes and its target genes. Moreover, the observed changes in gene expression after the different treatments indicate that the investigated genes may not play a principal role in cell migration. In future experiments, it may be interesting to focus on the protein expression of the genes to achieve a better understanding of how the cell may be affected in functional terms.

Although the role of VEGFA and MMP9 is not specifically in migration, they do play a role in the entire EMT process. Together with the expression of SNAIL, these three genes provide an overview of the different EMT regulators and migration, possibly indicating in what way the EMT process is directed (pro/anti-migration). A significantly increased 
expression of VEGF and MMP9 was observed in MCF-7 cells $24 \mathrm{~h}$ after carbon ion exposure. This is consistent with a study by Kamlah et al, in which the gene expression of VEGF was increased in lung cancer cells $24 \mathrm{~h}$ after a 2-Gy dose of carbon ions (55). Gan et al reported an increased expression of SNAIL1 at $24 \mathrm{~h}$ after X-irradiation (56), whereas in the present study only non-significant changes in SNAIL expression were observed $24 \mathrm{~h}$ after X-ray exposure. In contrast to these migration-related gene expression data, MCF-7 cells exhibited a dose-dependent decrease in migration after carbon ion exposure. This may, however, be explained by the fact that we only investigated some of the genes involved in migration and invasion. For example, a microarray study was performed on PC3 cells, which also demonstrated that several other genes related to cell migration were significantly more downregulated after carbon ion irradiation rather than after X-rays (57). Therefore, it would be of interest to expand the panel of genes involved in migration and invasion, including ZEB1 and 2, N-cadherin, E-cadherin, MMP-2, fibronectin 1 and nexilin.

At present, only a few studies have been performed that compare the effect of X-rays and carbon ions on breast cancer cell survival $(58,59)$. Our results are consistent with these studies, showing that carbon ions are more effective compared with X-rays in decreasing MCF-7 cell survival (RBE $\sim 2$ at $10 \%$ survival for our data). Similar RBE values have also been observed for other cell lines treated with carbon ions with similar LET values $(\sim 70 \mathrm{keV} / \mu \mathrm{m})(60,61)$. In addition, PTCH1 and GLI1, two indicators of Hh pathway activity, did not display significant changes in gene expression up to $24 \mathrm{~h}$ after irradiation with either X-rays or carbon ions. The Hh pathway is indirectly involved in cell survival, as some of its target genes are involved in cell survival. However, our data demonstrated that the Hh pathway, due to its low activity, only plays a minor role in the survival of MCF-7 cells in response to either X-ray or carbon ion exposure.

Combining radiation therapy with targeted therapies may decrease radiation-induced side-effects, as these drugs may sensitise cancer cells to radiation, thereby making it possible to use lower radiation doses to achieve the same tumour control rate. Thus far, only a few targeted therapies have been tested in combination with particle irradiation in vitro. The combination of radiation with the $\mathrm{Hh}$ inhibitor GANT61 has only been studied in vitro in combination with photon radiation in a limited number of cancer types. To the best of our knowledge, this is the first study to investigate the effect of X-ray and carbon ion radiation in combination with GANT61 on breast cancer cell survival. We observed that neither the combination of GANT61 with X-rays nor with carbon ions was able to sensitise MCF-7 cells. This is in contrast to previous studies, where GANT61 was able to sensitise renal cancer and prostate cancer cells to $\mathrm{X}$-irradiation $(29,40)$. A possible explanation as to why there was no observed radiosensitising effect of GANT61 may be because GANT61 at $10 \mu \mathrm{mol} / 1$ induces cytotoxicity in $\sim 80 \%$ of MCF-7 cells (Fig. 1). Therefore, the $20 \%$ of MCF-7 cells that survived GANT61 treatment (resistant MCF-7 cells) were studied, rather than the entire cell population. Although the majority of previous studies used a GANT61 concentration of $\sim 10 \mu \mathrm{mol} / 1$ to treat cancer cells, this concentration may still be too low to reveal changes in cell radiosensitivity. In addition, the lack of a radiosensitising effect may be due to the fact that, $24 \mathrm{~h}$ after the combination of X-rays or carbon ions with GANT61, the genes of the Hh pathway were not significantly downregulated (Fig. 6). This may indicate that the cancer cells would be able to proliferate in a manner similar to the cells without prior GANT61 treatment and, therefore, no differences were observed between the two treatments. For future experiments, it may be of interest to analyse the Hh pathway gene expression at 72 and $72 \mathrm{~h}+24 \mathrm{~h}$ of the GANT61 treatment alone.

In conclusion, the present study demonstrated that carbon ions are more effective in decreasing MCF-7 cell survival compared with X-rays, while MCF-7 cell migration was similarly affected by both radiation types. Furthermore, $\mathrm{X}$-rays were able to induce more significant changes in $\mathrm{Hh}$ pathway gene expression compared with carbon ions. In addition, GANT61 was not able to sensitise MCF-7 cells to X-ray or carbon ion radiation. However, the combination of GANT61 with X-ray or carbon ion radiation was more effective in decreasing cell migration compared with either radiation type alone. Further studies are required to determine whether breast cancer cells are a good model for investigating the combination of $\mathrm{Hh}$ inhibition and particle radiation. Moreover, additional cell lines must be included for further verification of these results in a wide spectrum of breast cancer types.

\section{Acknowledgements}

The authors would like to thank the iPAC committee of the Grand Accélérateur National d'Ions Lourds (GANIL, Caen, France) for the carbon ion beam time granted (P1006-H) and the staff of the LARIA, CIRIL (GANIL) for allowing us access to and use of their facility. We would also like to thank Bart Marlein, Michel Doms and Raf Aerts for their continued assistance during the $\mathrm{X}$-irradiation sessions at $\mathrm{SCK} \cdot \mathrm{CEN}$.

\section{Funding}

$\mathrm{KK}$ is a recipient of a $\mathrm{SCK} \cdot \mathrm{CEN}-\mathrm{KUL} \mathrm{PhD}$ grant. $\mathrm{KK}, \mathrm{NB}$, BB and RV received a Horizon 2020427 travel grant (no. 654002) for experiments at GANIL. KH is a clinical research fellow of the Research Foundation Flanders, Belgium.

\section{Availability of materials and data}

All the datasets generated and analysed in the present study are included in this published article.

\section{Authors' contributions}

KK performed experiments at $\mathrm{SCK} \bullet \mathrm{CEN}$, Belgium and GANIL, France. MM and SI designed the experimental set-up. $\mathrm{NB}, \mathrm{BB}, \mathrm{RV}$ and GL helped with experiments performed at GANIL. AJ helped with qPCR experiments. SB, SI, KH and MM contributed to the design of the study, as well as with interpretation of obtained data. All co-authors critically reviewed and approved the final version to be submitted to this journal. 


\section{Ethics approval and consent to participate}

Not applicable.

\section{Patient consent for publication}

Not applicable.

\section{Competing interests}

The authors declare that they have no competing interests.

\section{References}

1. Durante $M$ and Loeffler JS: Charged particles in radiation oncology. Nat Rev Clin Oncol 7: 37-43, 2010

2. Suit H,DeLaney T, Goldberg S, Paganetti H, Clasie B, Gerweck L, Niemierko A, Hall E, Flanz J, Hallman J and Trofimov A: Proton vs carbon ion beams in the definitive radiation treatment of cancer patients. Radiother Oncol 95: 3-22, 2010.

3. Weyrather WK and Debus J: Particle beams for cancer therapy. Clin Oncol (R Coll Radiol) 15: S23-S28, 2003.

4. Hamada N: Recent insights into the biological action of heavy-ion radiation. J Radiat Res 50: 1-9, 2009.

5. PTCOG Patient Statistics. Particle Therapy Co-Operative Group (PTCOG), Villigen, 2016. https://www.ptcog.ch/index.php/ ptcog-patient-statistics.

6. Siegel RL, Miller KD and Jemal A: Cancer statistics, 2016. CA Cancer J Clin 66: 7-30, 2016.

7. Corbin $\mathrm{K}$ and Mutter R: Proton therapy for breast cancer: Progress \& pitfalls. Breast Cancer Management 7, 2018.

8. Menezes KM, Wang H, Hada M and Saganti PB: Radiation matters of the heart: A mini review. Front Cardiovasc Med 5: $83,2018$.

9. Akamatsu H, Karasawa K, Omatsu T, Isobe Y, Ogata R and Koba Y: First experience of carbon-ion radiotherapy for early breast cancer. Jpn J Radiol 32: 288-295, 2014

10. Weber DC, Abrunhosa-Branquinho A, Bolsi A, Kacperek A, Dendale R, Geismar D, Bachtiary B, Hall A, Heufelder J, Herfarth K, et al: Profile of European proton and carbon ion therapy centers assessed by the EORTC facility questionnaire. Radiother Oncol 124: 185-189, 2017.

11. Lorusso $G$ and Rüegg C: New insights into the mechanisms of organ-specific breast cancer metastasis. Semin Cancer Biol 22 226-233, 2012

12. Nicolini A, Giardino R, Carpi A, Ferrari P, Anselmi L, Colosimo S, Conte M, Fini M, Giavaresi G, Berti P and Miccoli P: Metastatic breast cancer: An updating. Biomed Pharmacother 60: 548-556, 2006.

13. Karhadkar SS, Bova GS, Abdallah N, Dhara S, Gardner D, Maitra A, Isaacs JT, Berman DM and Beachy PA: Hedgehog signalling in prostate regeneration, neoplasia and metastasis. Nature 431: 707-712, 2004

14. Gonnissen A, Isebaert S and Haustermans K: Hedgehog signaling in prostate cancer and its therapeutic implication. Int J Mol Sci 14: 13979-14007, 2013.

15. Kubo M, Nakamura M, Tasaki A, Yamanaka N, Nakashima H, Nomura M, Kuroki S and Katano M: Hedgehog signaling pathway is a new therapeutic target for patients with breast cancer. Cancer Res 64: 6071-6074, 2004.

16. O'Toole SA, Machalek DA, Shearer RF, Millar EK, Nair R, Schofield P, McLeod D, Cooper CL, McNeil CM, McFarland A, et al: Hedgehog overexpression is associated with stromal interactions and predicts for poor outcome in breast cancer. Cancer Res 71: 4002-4014, 2011.

17. Cui W, Wang LH, Wen YY, Song M, Li BL, Chen XL, Xu M, An SX, Zhao J, Lu YY, et al: Expression and regulation mechanisms of sonic hedgehog in breast cancer. Cancer Sci 101: 927-933, 2010

18. Chang L, Zhao D, Liu HB, Wang QS, Zhang P, Li CL, Du WZ, Wang HJ, Liu X, Zhang ZR and Jiang CL: Activation of sonic hedgehog signaling enhances cell migration and invasion by induction of matrix metalloproteinase-2 and -9 via the phosphoinositide-3 kinase/AKT signaling pathway in glioblastoma. Mol Med Rep 12: 6702-6710, 2015.
19. Chen Q, Gao G and Luo S: Hedgehog signaling pathway and ovarian cancer. Chin J Cancer Res 25: 346-353, 2013.

20. Yan R, Peng X, Yuan X, Huang D, Chen J, Lu Q, Lv N and Luo S: Suppression of growth and migration by blocking the hedgehog signaling pathway in gastric cancer cells. Cell Oncol (Dordr) 36 421-435, 2013.

21. Feldmann G, Dhara S, Fendrich V, Bedja D, Beaty R Mullendore M, Karikari C, Alvarez H, Iacobuzio-Donahue C, Jimeno A, et al: Blockade of hedgehog signaling inhibits pancreatic cancer invasion and metastases: A new paradigm for combination therapy in solid cancers. Cancer Res 67: 2187-2196, 2007.

22. Isohata N, Aoyagi K, Mabuchi T, Daiko H, Fukaya M, Ohta H, Ogawa K, Yoshida T and Sasaki H: Hedgehog and epithelial-mesenchymal transition signaling in normal and malignant epithelial cells of the esophagus. Int J Cancer 125: 1212-1221, 2009.

23. Yoo YA, Kang MH, Lee HJ, Kim BH, Park JK, Kim HK, Kim JS and Oh SC: Sonic hedgehog pathway promotes metastasis and lymphangiogenesis via activation of Akt, EMT, and MMP-9 pathway in gastric cancer. Cancer Res 71: 7061-7070, 2011.

24. Lin Z, Li S, Sheng H, Cai M, Ma LY, Hu L, Xu S, Yu LS and Zhang N: Suppression of GLI sensitises medulloblastoma cells to mitochondria-mediated apoptosis. J Cancer Res Clin Oncol 142: 2469-2478, 2016

25. Chen Q, Xu R, Zeng C, Lu Q, Huang D, Shi C, Zhang W, Deng L, Yan R, Rao H, et al: Down-regulation of Gli transcription factor leads to the inhibition of migration and invasion of ovarian cancer cells via integrin $\beta 4$-mediated FAK signaling. PLoS One 9: e88386, 2014

26. Magistri P, Battistelli C, Strippoli R, Petrucciani N, Pellinen T, Rossi L, Mangogna L, Aurello P, D'Angelo F, Tripodi M, et al: SMO inhibition modulates cellular plasticity and invasiveness in colorectal cancer. Front Pharmacol 8: 956, 2018.

27. Yue D, Li H, Che J, Zhang Y, Tseng HH, Jin JQ, Luh TM, Giroux-Leprieur E, Mo M, Zheng Q, et al: Hedgehog/Gli promotes epithelial-mesenchymal transition in lung squamous cell carcinomas. J Exp Clin Cancer Res 33: 34, 2014.

28. Zeng J, Aziz K, Chettiar ST, Aftab BT, Armour M, Gajula R, Gandhi N, Salih T, Herman JM, Wong J, et al: Hedgehog pathway inhibition radiosensitises non-small cell lung cancers Int J Radiat Oncol Biol Phys 86: 143-149, 2013.

29. Gonnissen A, Isebaert S, McKee CM, Dok R, Haustermans K and Muschel RJ: The hedgehog inhibitor GANT61 sensitises prostate cancer cells to ionizing radiation both in vitro and in vivo. Oncotarget 7: 84286-84298, 2016.

30. Teichman J, Dodbiba L, Thai H, Fleet A, Morey T, Liu L, McGregor M, Cheng D, Chen Z, Darling G, et al: Hedgehog inhibition mediates radiation sensitivity in mouse xenograft models of human esophageal adenocarcinoma. PLoS One 13: e0194809, 2018.

31. Tsai CL, Hsu FM, Tzen KY, Liu WL, Cheng AL and Cheng JC: Sonic Hedgehog inhibition as a strategy to augment radiosensitivity of hepatocellular carcinoma. J Gastroenterol Hepatol 30: 1317-1324, 2015.

32. Franco AI, Eastwick G, Farah R, Heyboer M, Lee M and Aridgides P: Upfront radiotherapy with concurrent and adjuvant vismodegib is effective and well-tolerated in a patient with advanced, multifocal basal cell carcinoma. Case Rep Dermatol Med 2018: 2354146, 2018

33. Schulze B, Meissner M, Ghanaati S, Burck I, Rodel C and Balermpas P: Hedgehog pathway inhibitor in combination with radiation therapy for basal cell carcinomas of the head and neck: First clinical experience with vismodegib for locally advanced disease. Strahlenther Onkol 192: 25-31, 2016.

34. Pollom EL, Bui TT, Chang AL, Colevas AD and Hara WY: Concurrent vismodegib and radiotherapy for recurrent, advanced basal cell carcinoma. JAMA Dermatol 151: 998-1001, 2015.

35. Raleigh DR, Algazi A, Arron ST, Neuhaus IM and Yom SS: Induction hedgehog pathway inhibition followed by combined-modality radiotherapy for basal cell carcinoma. Br J Dermatol 173: 544-546, 2015.

36. Atwood SX, Chang AL and Oro AE: Hedgehog pathway inhibition and the race against tumor evolution. J Cell Biol 199: 193-197, 2012.

37. Rudin CM, Hann CL, Laterra J, Yauch RL, Callahan CA, Fu L, Holcomb T, Stinson J, Gould SE, Coleman B, et al: Treatment of medulloblastoma with hedgehog pathway inhibitor GDC-0449. N Engl J Med 361: 1173-1178, 2009.

38. Chang AL and Oro AE: Initial assessment of tumor regrowth after vismodegib in advanced Basal cell carcinoma. Arch Dermatol 148: 1324-1325, 2012. 
39. Gonnissen A, Isebaert S, McKee CM, Muschel RJ and Haustermans K: The effect of metformin and GANT61 combinations on the radiosensitivity of prostate cancer cells. Int J Mol Sci 18: E399, 2017.

40. Zhou J, Wu K, Gao D, Zhu G, Wu D, Wang X, Chen Y, Du Y, Song W, Ma Z, et al: Reciprocal regulation of hypoxia-inducible factor $2 \alpha$ and GLI1 expression associated with the radioresistance of renal cell carcinoma. Int J Radiat Oncol Biol Phys 90: 942-951, 2014.

41. Lesueur P, Chevalier F, El-Habr EA, Junier MP, Chneiweiss H, Castera L, Muller E, Stefan D and Saintigny Y: Radiosensitization effect of talazoparib, a parp inhibitor, on glioblastoma stem cells exposed to low and high linear energy transfer radiation. Sci Rep 8: 3664, 2018.

42. Soule HD, Vazguez J, Long A, Albert S and Brennan M: A human cell line from a pleural effusion derived from a breast carcinoma. J Natl Cancer Inst 51: 1409-1416, 1973.

43. Durantel F, Balanzat E, Cassimi A, Chevalier F, Ngono-Ravache Y, Madi T, Poully JC, Ramillon JM, Rothard H, Ropars F, et al: Dosimetry for radiobiology experiments at GANIL. Nuclear instruments and methods in physics research section A: Accelerators, Spectrometers, Detectors and Associated Equipment. Elsevier 816: 70-77, 2016.

44. Suetens A, Moreels M, Quintens R, Soors E, Buset J, Chiriotti S, Tabury K, Gregoire V and Baatout S: Dose- and time-dependent gene expression alterations in prostate and colon cancer cells after in vitro exposure to carbon ion and X-irradiation. J Radiat Res 56: 11-21, 2015.

45. Pfaffl MW: A new mathematical model for relative quantification in real-time RT-PCR. Nucleic Acids Res 29: e45, 2001.

46. Moncharmont C, Levy A, Guy JB, Falk AT, Guilbert M, Trone JC, Alphonse G, Gilormini M, Ardail D, Toillon RA, et al: Radiation-enhanced cell migration/invasion process: A review. Crit Rev Oncol Hematol 92: 133-142, 2014.

47. Fujita M, Imadome K, Shoji Y, Isozaki T, Endo S, Yamada S and Imai T: Carbon-ion irradiation suppresses migration and invasiveness of human pancreatic carcinoma cells MIAPaCa-2 via Racl and RhoA degradation. Int J Radiat Oncol Biol Phys 93: 173-180, 2015.

48. Fujita M, Yamada S and Imai T: Irradiation induces diverse changes in invasive potential in cancer cell lines. Semin Cancer Biol 35: 45-52, 2015.

49. Matsumoto Y, Furusawa Y, Uzawa A, Hirayama R, Koike S Ando K, Tsuboi K and Sakurai H: Antimetastatic effects of carbon-ion beams on malignant melanomas. Radiat Res 190: 412-423, 2018

50. Clarke MF, Dick JE, Dirks PB, Eaves CJ, Jamieson $\mathrm{CH}$, Jones DL, Visvader J, Weissman IL and Wahl GM: Cancer stem cells-perspectives on current status and future directions: AACR Workshop on cancer stem cells. Cancer Res 66: 9339-9344, 2006
51. Zhang X, Li X, Zhang N, Yang Q and Moran MS: Low doses ionizing radiation enhances the invasiveness of breast cancer cells by inducing epithelial-mesenchymal transition. Biochem Biophys Res Commun 412: 188-192, 2011.

52. Chapman JD, Doern SD, Reuvers AP, Gillespie CJ, Chatterjee A, Blakely EA, Smith KC and Tobias CA: Radioprotection by DMSO of mammalian cells exposed to X-rays and to heavy charged-particle beams. Radiat Environ Biophys 16: 29-41, 1979.

53. Goddu SM, Narra VR, Harapanhalli RS, Howell RW and Rao DV: Radioprotection by DMSO against the biological effects of incorporated radionuclides in vivo-Comparison with other radioprotectors and evidence for indirect action of Auger electrons. Acta Oncol 35: 901-907, 1996.

54. Fushimi K, Uzawa K, Ishigami T, Yamamoto N, Kawata T, Shibahara T, Ito H, Mizoe JE, Tsujii $H$ and Tanzawa $H$ : Susceptible genes and molecular pathways related to heavy ion irradiation in oral squamous cell carcinoma cells. Radiother Oncol 89: 237-244, 2008

55. Kamlah F, Hänze J, Arenz A, Seay U, Hasan D, Juricko J, Bischoff B, Gottschald OR, Fournier C, Taucher-Scholz G, et al: Comparison of the effects of carbon ion and photon irradiation on the angiogenic response in human lung adenocarcinoma cells. Int J Radiat Oncol Biol Phys 80: 1541-1549, 2011.

56. Gan GN, Eagles J, Keysar SB, Wang G, Glogowska MJ, Altunbas C, Anderson RT, Le PN, Morton JJ, Frederick B, et al: Hedgehog signaling drives radioresistance and stroma-driven tumor repopulation in head and neck squamous cancers. Cancer Res 74: 7024-7036, 2014.

57. Suetens A, Moreels M, Quintens R, Chiriotti S, Tabury K, Michaux A, Gregoire V and Baatout S: Carbon ion irradiation of the human prostate cancer cell line PC3: A whole genome microarray study. Int J Oncol 44: 1056-1072, 2014.

58. Zhou X, Zhang X, Xie Y, Tanaka K, Wang B and Zhang $\mathrm{H}$ DNA-PKcs inhibition sensitises cancer cells to carbon-ion irradiation via telomere capping disruption. PLoS One 8: e72641, 2013.

59. Sai S, Vares G, Kim EH, Karasawa K, Wang B, Nenoi M, Horimoto $\mathrm{Y}$ and Hayashi $\mathrm{M}$ : Carbon ion beam combined with cisplatin effectively disrupts triple negative breast cancer stem-like cells in vitro. Mol Cancer 14: 166, 2015.

60. Suzuki M, Kase Y, Yamaguchi H, Kanai T and Ando K: Relative biological effectiveness for cell-killing effect on various human cell lines irradiated with heavy-ion medical accelerator in Chiba (HIMAC) carbon-ion beams. Int J Radiat Oncol Biol Phys 48 241-250, 2000

61. Wada M, Suzuki M, Liu C, Kaneko Y, Fukuda S, Ando K and Matsufuji N: Modeling the biological response of normal human cells, including repair processes, to fractionated carbon beam irradiation. J Radiat Res 54: 798-807, 2013. 